\title{
Reduced oxidation rates of ingested glucose during prolonged exercise with low endogenous $\mathrm{CHO}$ availability.
}

Citation for published version (APA):

Jeukendrup, A. E., Borghouts, L., Saris, W. H. M., \& Wagenmakers, A. J. M. (1996). Reduced oxidation rates of ingested glucose during prolonged exercise with low endogenous $\mathrm{CHO}$ availability. Journal of Applied Physiology, 81, 1952-1957. https://doi.org/10.1152/jappl.1996.81.5.1952

Document status and date:

Published: 01/01/1996

DOI:

10.1152/jappl.1996.81.5.1952

Document Version:

Publisher's PDF, also known as Version of record

\section{Please check the document version of this publication:}

- A submitted manuscript is the version of the article upon submission and before peer-review. There can be important differences between the submitted version and the official published version of record. People interested in the research are advised to contact the author for the final version of the publication, or visit the DOI to the publisher's website.

- The final author version and the galley proof are versions of the publication after peer review.

- The final published version features the final layout of the paper including the volume, issue and page numbers.

Link to publication

\footnotetext{
General rights rights.

- You may freely distribute the URL identifying the publication in the public portal. please follow below link for the End User Agreement:

www.umlib.nl/taverne-license

Take down policy

If you believe that this document breaches copyright please contact us at:

repository@maastrichtuniversity.nl

providing details and we will investigate your claim.
}

Copyright and moral rights for the publications made accessible in the public portal are retained by the authors and/or other copyright owners and it is a condition of accessing publications that users recognise and abide by the legal requirements associated with these

- Users may download and print one copy of any publication from the public portal for the purpose of private study or research.

- You may not further distribute the material or use it for any profit-making activity or commercial gain

If the publication is distributed under the terms of Article $25 \mathrm{fa}$ of the Dutch Copyright Act, indicated by the "Taverne" license above, 


\title{
Reduced oxidation rates of ingested glucose during prolonged exercise with low endogenous $\mathrm{CHO}$ availability
}

\author{
ASKER E. J EUKENDRUP, LARS B. BORGHOUTS, \\ WIM H. M. SARIS, AND ANTON J. M. WAGENMAKERS \\ Department of Human Biology, Nutrition Research Centre, \\ University Maastricht, NL-6200 MD Maastricht, The Netherlands
}

\begin{abstract}
J eukendrup, Asker E., Lars B. Borghouts, Wim H. M. Saris, and Anton J . M. Wagenmakers. Reduced oxidation rates of ingested glucose during prolonged exercise with low endogenous CHO availability. J . Appl. Physi ol . 81(5): 19521957, 1996.-This study investigated the effect of endogenous carbohydrate $(\mathrm{CHO})$ availability on oxidation rates of ingested glucose during moderate-intensity exercise. Seven well-trained cyclists performed two trials of $120 \mathrm{~min}$ of cycling exercisein random order at $57 \%$ maximal $\mathrm{O}_{2}$ consumption. Preexercise glycogen concentrations were manipulated by glycogen-lowering exercise in combination with $\mathrm{CHO}$ restriction [low-glycogen (LG) trial] or $\mathrm{CHO}$ loading [moderateto-high-glycogen (HG) trial]. In the LG and HG trials, subjects ingested $4 \mathrm{ml} / \mathrm{kg}$ body wt of an $8 \%$ corn-derived glucose solution of high natural ${ }^{13} \mathrm{C}$ abundance at the start, followed by boluses of $2 \mathrm{ml} / \mathrm{kg}$ every $15 \mathrm{~min}$. The third trial, in which potato-derived glucose was ingested, served as a control test for background correction. Exogenous glucose oxidation rates were calculated from the ${ }^{13} \mathrm{C}$ enrichment of the ingested glucose and of the breath $\mathrm{CO}_{2}$. Total $\mathrm{CHO}$ oxidation was lower in the LG trial than in the HG trial during 60-120 min of exercise [84 \pm 7 (SE) vs. $116 \pm 8 \mathrm{~g} ; \mathrm{P}<0.05$ ]. Exogenous $\mathrm{CHO}$ oxidation in this period was $28 \%$ lower in the LG trial compared with the HG trial. Maximal exogenous oxidation rates were also lower $(P<0.05)$ in the $L G$ trial $(0.64 \pm 0.05$ $\mathrm{g} / \mathrm{min}$ ) than in the $\mathrm{HG}$ trial $(0.88 \pm 0.04 \mathrm{~g} / \mathrm{min})$. This decreased utilization of exogenous glucose was accompanied by increased plasma free fatty acid levels (2-3 times higher) and lower insul in concentrations. It is concluded that glycogenlowering exercise, performed the evening before an exercise bout, in combination with $\mathrm{CHO}$ restriction leads to a reduction of the oxidation rate of ingested glucose during moderateintensity exercise.
\end{abstract}

exogenous glucose oxidation; carbon-13; breath test; stable isotopes; substrate utilization; carbohydrate

INGESTION OF CARBOHYDRATE (CHO) has become common practice for endurance athletes during prol onged exercise to improve performance. Carefully conducted studies showed that glucose ingestion during exercise improved performance both in intermittent (35) and in prolonged continuous exerise $(3,7)$. During intermittent exercise, the increased time to exhaustion with $\mathrm{CHO}$ ingestion has been attributed to a sparing of muscle glycogen stores (35). However, during prol onged continuous exercise, muscle glycogen breakdown is not affected by $\mathrm{CHO}$ ingestion, and the enhanced performance is attributed to a maintainance of blood glucose levels and high rates of $\mathrm{CHO}$ oxidation during the late phases of exercise (3). It has been shown that the ingested $\mathrm{CHOs}$ reduce hepatic glucose output (i.e., spare liver glycogen) $(2,23)$. A larger contribution of exogenous $\mathrm{CHOs}$ is believed to be more beneficial to endurance performance because endogenous substrates are conserved more. In this context, it is important to know the factors that affect exogenous $\mathrm{CHO}$ oxidation.

Therefore, the oxidation of ingested $\mathrm{CHO}$ s has been intensively investigated since the late 1970s by using stable-isotope techniques involving the ingestion of naturally labeled $\left[{ }^{13} \mathrm{C}\right]$ glucose $(21,25,33)$. F rom a large number of studies it appeared that the extent to which these $\mathrm{CHOs}$ are oxidized is dependent on several factors, including the amount and type of $\mathrm{CHO}$ ingested, the feeding schedule, and the exercise intensity. However, at present, the effect of variation of preexercise glycogen levels on exogenous glucose oxidation is unclear.

To our knowledge, only two studies attempted to address this question. Ravussin et al. (28) observed no significant differences in the oxidation rates of ingested $\mathrm{CHOs}$ in a group of glycogen-depleted subjects vs. a control group during low-jntensity exercise at $40 \%$ maximal $\mathrm{O}_{2}$ consumption $\left(\mathrm{VO}_{2 \max }\right)$. However, the study had no crossover design, which, when individual variations are taken into account, weakens the results. Massicotte et al. (22) studied exogenous $\mathrm{CHO}$ oxidation during $2 \mathrm{~h}$ of exercise at moderate intensity $(52 \%$ $V_{O_{2 m a x}}$ ) in fed and fasted conditions and did not find differences in the oxidation rates of ingested glucose. However, the primary effect of overnight fasting is emptying of the liver glycogen stores, whereas muscle glycogen stores change little. Therefore, the fact that thesestudies did not show an effect of glycogen availability on exogenous $\mathrm{CHO}$ oxidation may be caused by experimental or methodological limitations of these studies.

Although little information is available on effect of preexercise glycogen levels on the oxidation rates of exogenous $\mathrm{CHOs}$, there are some reports on the effect of muscle glycogen on blood glucose uptake by the muscle in situations without $\mathrm{CHO}$ ingestion. Gollnick et al. (10) and Maehlum et al. (19) observed a higher glucose uptake in a leg with a low muscle glycogen content compared with a leg with normal glycogen by measuring arteriovenous differences across the exercising leg. On the other hand, others showed decreased muscle glucose uptake or $\mathrm{CHO}$ oxidation when plasma free fatty acid (FFA) levels were el evated $(6,12,30,32$ ). Such an elevation of plasma FFAs al ways occurs when the glycogen depletion is achieved by exercise the night before and is followed by fasting or a low-CHO diet until the final exercise the morning after.

Therefore, this study investigated the effect of glycogen-lowering exercise vs. CHO loading on oxidation 
rates of ingested glucose during 2-h cycling exercise at $57 \% \mathrm{Vo}_{2 \max }$.

\section{MATERIALS AND METHODS}

Subjects. Seven well-trained cyclists or triathletes [age $25 \pm 1.4$ (SE) yr, wt $72.2 \pm 1.2 \mathrm{~kg}$ participated in this study. The nature and the risks of the experimental procedures were explained to the subjects, and their written informed consent was obtained. Thestudy was approved by theE thical Committee of the University Maastricht.

Preexercise testing. Subjects' $\mathrm{VO}_{2 \max }$ values were measured on an electronically braked cycle ergometer (Lode Excalibur, Groningen, The Netherlands) during an incremental exhaustive exercise test (18) $1 \mathrm{wk}$ before the first experimental trial. Maximal workload (Wmax) averaged $414 \pm 13.7 \mathrm{~W}$, and $\mathrm{VO}_{2 \max }$ averaged $5.1 \pm 0.2 \mathrm{l} / \mathrm{min}$. The results of this initial test were used to determine the $50 \%$ Wmax workload, which was later used in the experimental trials.

Experimental trials. To obtain a situation with low endogenous $\mathrm{CHO}$ availability (i.e., glycogen levels) and a situation with moderate-to-high endogenous $\mathrm{CHO}$ availability, a similar protocol was applied as previously described (15). Each subject performed three trials, a low-glycogen (LG) trial, a normal-to-high-glycogen (HG) trial, and a control (C) trial, each separated by at least 7 days. The trials consisted of 120 min of cycling at $50 \% \mathrm{Wmax}\left(\sim 57 \% \mathrm{~V}_{\mathrm{O}_{2} \max }\right)$. The order of the trials was determined by counterbalancing.

The evening before the LG trial, subjects followed a glycogen-depletion protocol ( $13 \mathrm{~h}$ preexercise). The depletion trial, starting at 8:00 P.M., consisted of an intermittent cycling exercise protocol, consisting of 2-min bouts at $90 \%$ Wmax, interspersed with $2 \mathrm{~min}$ at $50 \%$ Wmax. When the subjects were unable to complete the $2 \mathrm{~min}$ at $90 \%$ Wmax, the high workload was subsequently lowered to 80,70 , and finally $60 \%$ Wmax. The exercise was stopped when the $2 \mathrm{~min}$ at $60 \%$ Wmax could not be completed anymore. This protocol has previously been shown to be effective in lowering glycogen levels ( $<35 \mu \mathrm{mol} / \mathrm{g}$ wet wt) (17). During the LG trials, the subjects were allowed to consume water ad libitum. Subjects were al lowed to eat two crackers with cheese $(14 \mathrm{~g} \mathrm{CHO}, 4 \mathrm{~g}$ fat, $6 \mathrm{~g}$ protein) and to drink a cup of decaffeinated coffee or tea in the time between completion of the glycogen-depletion protocol and going to sleep.

During the HG trial, subjects were instructed to refrain from any vigorous exercise the day before the experimental trial. The evening preceding the experimental trials $(13 \mathrm{~h}$ preexercise) the subjects received a $\mathrm{CHO}$-rich meal predominantly consisting of pasta $(4,000-5,000 \mathrm{~kJ} ; 250-300 \mathrm{~g} \mathrm{CHO}$, $15 \mathrm{~g}$ fat, $20 \mathrm{~g}$ protein) at the laboratory to ensure a high-CHO intake and concomitant optimal glycogen stores.

A third test was employed that served as a $C$ trial to allow for corrections for changes in breath ${ }^{13} \mathrm{CO}_{2}$ background enrichment during exercise. In addition, subjects were instructed to not consume any products with a high natural abundance of ${ }^{13} \mathrm{C}$ during the entire experimental period. This was done to minimize a shift in background enrichment due to changes in endogenous substrate utilization (29, 33, 34). Furthermore, subjects were instructed to keep their diet as constant as possible the days before the trials. Furthermore, to prevent underestimation of calculated exogenous glucose oxidation rates due to isotopic dillution of ${ }^{13} \mathrm{CO}_{2}$ in the bicarbonate pool, results of the first $60 \mathrm{~min}$ were neglected and all calculations were performed for the 60- to 120-min exercise period.

Protocol. Subjects reported to the laboratory at 8:00 A.M. after an overnight fast, and beforeall trials a small standardized breakfast of two crackers with cheese was provided (14 g CHO, $4 \mathrm{~g}$ fat, $6 \mathrm{~g}$ protein). A Teflon catheter (Baxter Quick
Cath Dupont) was inserted into an antecubital vein, and at 8:30 A.M. a resting blood sample was drawn. Resting breath gases were collected (Oxycon $\beta$, Mijnhardt, The Netherlands), and duplicate vacutainer tubes were filled directly from the mixing chamber to determine the ${ }^{13} \mathrm{C} /{ }^{12} \mathrm{C}$ ratio in expired $\mathrm{CO}_{2}$. At 8:50 A.M., subjects started a warm-up of $5 \mathrm{~min}$ at 100 W followed by $5 \mathrm{~min}$ at $40 \%$ Wmax. At 9.00 A.M., the workload was increased to $50 \%$ Wmax for $120 \mathrm{~min}$. During the 1st min, subjects drank an initial bolus $(8 \mathrm{ml} / \mathrm{kg}=46.2 \pm 0.7 \mathrm{~g})$ of an $8 \%$ glucose solution. Thereafter, every $15 \mathrm{~min}$ a beverage vol ume of $2 \mathrm{ml} / \mathrm{kg}$ ( $=11.5 \pm 0.2 \mathrm{~g}$ ) was provided. The average amount of glucose provided during the $120 \mathrm{~min}$ of exercise was $127.1 \pm 5.0 \mathrm{~g}$. Blood samples were drawn at 30-min intervals until the end of exercise. Expiratory gases were collected every $15 \mathrm{~min}$. Two subjects were tested on the same day, starting the protocol 10 min apart.

Glucose sol utions. To quantify exogenous glucose oxidation, solutions were prepared from corn-derived glucose (Amylum), which has a high natural abundance of ${ }^{13} \mathrm{C}$. The ${ }^{13} \mathrm{C}$ enrichment of the glucose was $-11.2 \delta \%$ ovs. Pee Dee Bellimnitella (PDB) and was determined by an on-line combustion-isotope ratio mass spectrometer (IRMS; F innigan MAT 252, Bremen, Germany). During the control trial, subjects ingested an $8 \%$ solution prepared from potato-derived glucose (AVEBE). This glucose had a ${ }^{13} \mathrm{C}$ enrichment of $-26.1 \delta \%$ ovs. PDB, which is similar to the ${ }^{13} \mathrm{C}$ enrichment of expired air of E uropeans (33).

Analysis. Blood $(5 \mathrm{ml})$ was collected into EDTA-containing tubes and was centrifuged for $4 \mathrm{~min}$ at $4^{\circ} \mathrm{C}$. Aliquots of plasma were frozen immediately in liquid nitrogen and stored at $-40^{\circ} \mathrm{C}$ until analysis of glucose (Uni Kit III 0710970, Roche), lactate (11), and FFAs (Wako NEFA-C test kit, Wako Chemicals, Neuss, Germany), which were performed with the COBAS BIO semiautomatic analyzer. Insulin was analyzed by radioimmunoassay (Linco). From indirect calorimetry [respiratory quotient, $\mathrm{O}_{2}$ consumption $\left(\mathrm{VO}_{2}\right)$ ] and stableisotope measurements $\left({ }^{13} \mathrm{CO}_{2} /{ }^{12} \mathrm{CO}_{2}\right)$ (IRMS, Finnigan MAT 252), total energy expenditure and oxidation rates of total fat, total $\mathrm{CHOs}$, and exogenous glucose were cal culated.

Calculations. From $\mathrm{CO}_{2}$ production $\left(\mathrm{V}_{\mathrm{CO}_{2}}\right)$ and $\mathrm{V}_{2}, \mathrm{CHO}$ and fat oxidation rates were calculated by using stoichiometric equations (24). The isotopic enrichment was expressed as the $\delta \%$ difference between the ${ }^{13} \mathrm{C} /{ }^{12} \mathrm{C}$ ratio of the sample and a known laboratory reference standard according to the formula of Craig (8)

$$
\delta^{13} \mathrm{C}=\left[\left(\frac{{ }^{13} \mathrm{C} /{ }^{12} \mathrm{C} \text { sample }}{{ }^{13} \mathrm{C} /{ }^{12} \mathrm{C} \text { standard }}\right)-1\right] \times 10^{3}
$$

The $\delta^{13} \mathrm{C}$ was then related to an international standard (PDB).

The amount of glucose oxidized was cal culated according to the formula

$$
\text { exogenous glucose oxidation }=\dot{\mathrm{V}} \mathrm{CO}_{2} \cdot\left(\frac{\delta_{\exp }-\delta \mathrm{C}}{\delta_{\text {ing }}-\delta \mathrm{C}}\right)\left(\frac{1}{\mathrm{k}}\right)
$$

in which $\delta \mathrm{C}$ is the ${ }^{13} \mathrm{C}$ enrichment of expired air in the control test (background), $\delta_{\text {exp }}$ is the ${ }^{13} \mathrm{C}$ enrichment of expired air during exercise at different time points, $\delta_{\text {ing }}$ is the ${ }^{13} \mathrm{C}$ enrichment of the ingested glucose, and $\mathrm{k}$ is the amount of $\mathrm{CO}_{2}$ (in liters) produced by the oxidation of $1 \mathrm{~g}$ glucose $(\mathrm{k}=$ 0.7467 I $\mathrm{CO}_{2} / \mathrm{g}$ glucose).

Statistics. Analysis of variance for repeated measures was used to compare differences in substrate utilization and in blood-related parameters among the three trials. A Scheffé's post hoc test was used in the event of a significant $(P<0.05)$ F-ratio. 
Fig. 1. Plasma glucose (A), insulin (B), free fatty acid (FFA; C), and lactate concentrations (D) during exercise at $57 \%$ maximal $\mathrm{O}_{2}$ consumption after carbohydrate depletion and a carbohydraterestricted diet [low-glycogen (LG) trial; $\square$ ] and after glycogen loading [moderateto-high glycogen (HG) trial; $\mathbf{\square}$. Values are means $\pm \mathrm{SE}$. * Significantly different from LG trial, $P<0.05$.
A

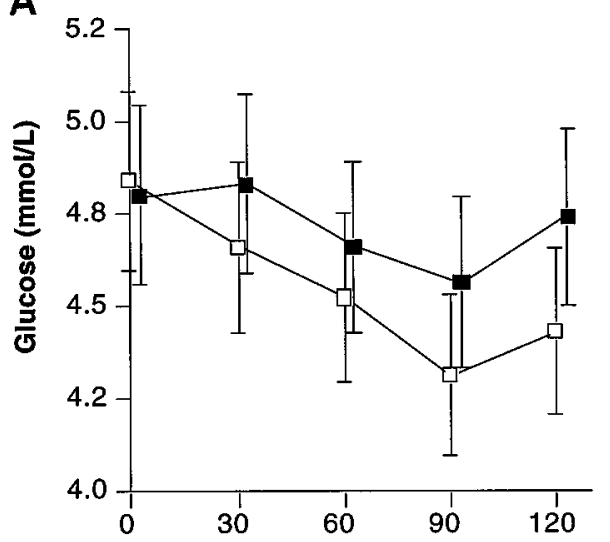

C

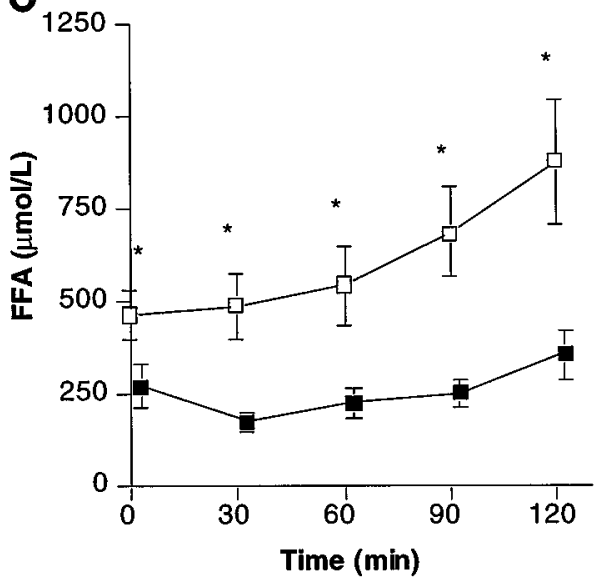

B

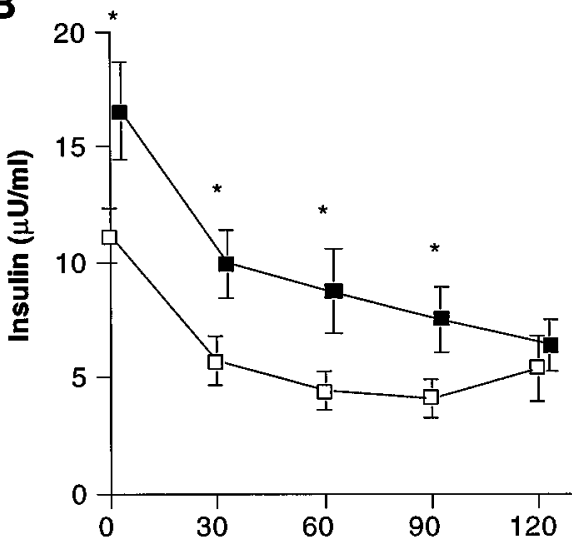

D

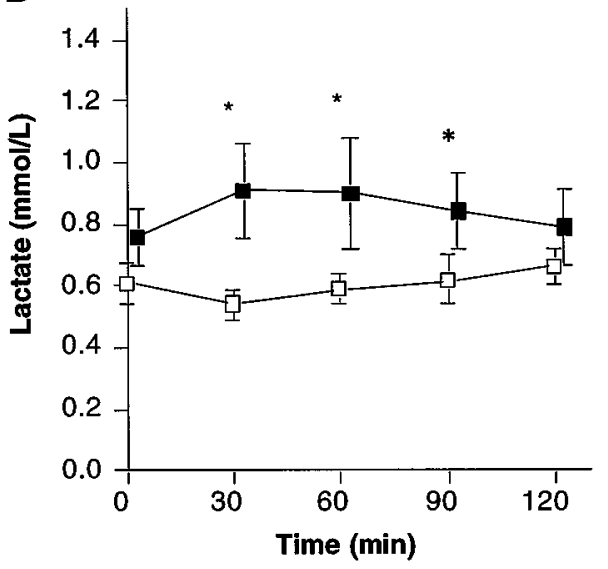

\section{RESULTS}

Blood parameters. No differences were observed in resting plasma glucose concentrations between the $L G$ and HG trials (Fig. 1). Plasma glucose tended to be lower in the LG trials and tended to decrease toward the end of exercise. However, these differences were not statistically significant. Plasma insulin levels were significantly lower at the start of exercise in the LG trial compared with the HG tial (Fig. 1). Although in both conditions plasma insulin concentrations decreased to very low levels, the difference between the two trials remained, except at $120 \mathrm{~min}$. Plasma FFA levels were significantly higher at rest and during exercise in the LG trial compared with the HG trial (Fig. 1). Plasma FFAs did not increase during the HG and $C$ trials (concentrations were $\sim 200 \mu \mathrm{mol} / \mathrm{l}$ ) but increased gradually during exercise in the LG trial, reaching moderately high FFA levels $(700-900 \mu \mathrm{mol} / \mathrm{l})$. At all time points, plasma FFA concentrations were significantly higher in the LG trial.

Whereas at rest no differences could be observed between the trials, during exercise plasma lactate concentrations were significantly lower in the LG vs. the HG trial, except at 120 min (Fig. 1).

Indirect calorimetry. During exercise, fat oxidation was significantly higher in the LG trial and $\mathrm{CHO}$ oxidation was concomitantly lower. $\mathrm{CHO}$ oxidation over the entire exercise period was $164 \pm 15 \mathrm{~g}$ in the LG trial and $219 \pm 14 \mathrm{~g}$ in the $\mathrm{HG}$ trial, indicating that $\mathrm{CHO}$ contributed $25 \%$ less to energy expenditure in the glycogen-depleted state. This decreased utilization of $\mathrm{CHO}$ was completely compensated by fat oxidation because no differences were observed in total energy expenditure between the trials. An overview of substrate utilization in the HG and LG trials during the 60- to 120-min period is listed in Table 1. The relative contribution of substrates to total energy expendidure is depicted in Fig. 2.

Exogenous glucose oxi dation. Background ${ }^{13} \mathrm{C}$ enrichment measured from the resting breath samples was $-26.5 \pm 0.6 \delta \%$ ovs. PDB. Changes in isotopic composition of expired $\mathrm{CO}_{2}$ in response to exercise are shown in Fig. 3. With ingestion of the corn-derived glucose in the LG and $H G$ trials, the rise in ${ }^{13} \mathrm{C}$ was significant, reaching a $\delta \%$ ovs. PDB difference of $\sim 4$ toward the end

Table 1. Substrateutilization during exercise

\begin{tabular}{lcc}
\hline \hline & HG Trial & LG Trial \\
\hline Exogenous CHO,g & $49.3 \pm 1.6^{*}$ & $35.7 \pm 3.3$ \\
Endogenous CHO,g & $67.0 \pm 6.6^{*}$ & $48.3 \pm 6.9$ \\
Fat, g & $70.0 \pm 5.1^{*}$ & $91.1 \pm 8.2$ \\
\hline
\end{tabular}

Values are means \pm SE. Exogenous and endogenous carbohydrate (CHO) and fat oxidation are calculated for 60-120 min of exercise at $57 \%$ maximal $\mathrm{O}_{2}$ consumption after $\mathrm{CHO}$ depletion and $\mathrm{CHO}$ restricted diet ( $\mathrm{LG}$ trial) or after glycogen loading ( $\mathrm{HG}$ trial). *Significantly different from LG, $\mathrm{P}<0.05$. 


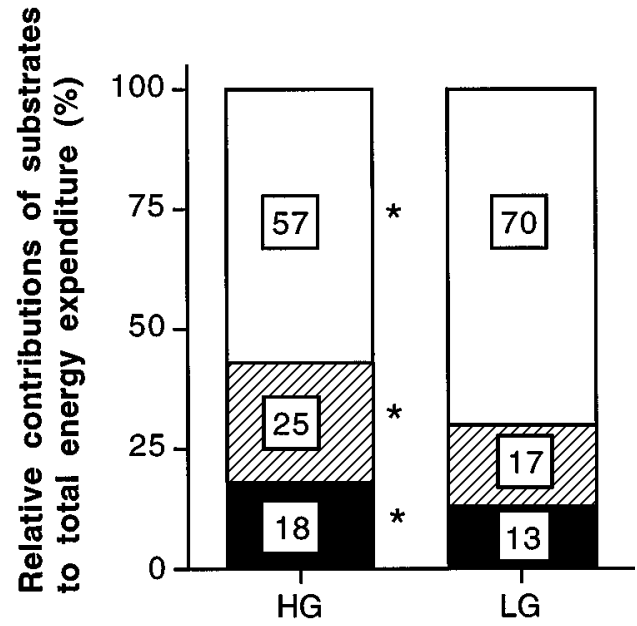

Fig. 2. Relative contributions of substrates to total energy expenditure (nos. in bars, \%). Relative contribution of exogenous carbohydrate oxidation (solid bar), endogenous carbohydrate oxidation (hatched bar), and fat oxidation (open bar) was calculated for 60-120 min of exercise at $57 \%$ maximal $\mathrm{O}_{2}$ consumption after carbohydrate depletion and carbohydrate-restricted diet (LG trial) or after glycogen loading (HG trial). *Significantly different from LG trial, P < 0.05 .

of 120 min of exercise (compared with resting breath sample). The changes in background enrichment during exercise in the $\mathrm{C}$ trial were $\sim 7-10 \%$ of the ${ }^{13} \mathrm{C}$ enrichment provoked by the exogenous glucose in the LG and HG trials. Therefore, a background correction was made for the calculation of exogenous glucose oxidation by using the data from the $C$ trial. Exogenous glucose oxidation showed a gradual increase over time both in the glycogen-depleted and CHO-loaded states (Fig. 3). Oxidation rates leveled off after $\sim 75 \mathrm{~min}$, and maximal oxidation rates of $0.64 \pm 0.05 \mathrm{~g} / \mathrm{min}$ (LG trial) and $0.88 \pm 0.04 \mathrm{~g} / \mathrm{min}$ (HG trial) were observed. Exogenous glucose oxidation was significantly lower in the LG compared with the HG experiment (35.7 \pm 3.3 and $49.3 \pm 1.6 \mathrm{~g}$ during $60-120 \mathrm{~min}$, respectively; Table 1).

\section{DISCUSSION}

The most remarkable finding of this study is that exogenous glucose oxidation was lower when the glycogen stores were reduced by strenuous exercise the day before the exercise trial and kept low by ingestion of a $\mathrm{CHO}$-restricted diet. Exogenous glucose oxidation was $28 \%$ lower in the LG trial compared with the HG trial: $36 \pm 3 \mathrm{~g}$ of glucose were oxidized during $60-120 \mathrm{~min}$ of exercise with low-glycogen stores, whereas $50 \pm 2 \mathrm{~g}$ were oxidized with normal-to-high glycogen stores. The glycogen-depletion protocol and $\mathrm{CHO}$ restriction caused large changes in substrate utilization. $F$ at contributed $57 \%$ to energy supply when subjects were $\mathrm{CHO}$ loaded (Fig. 2). With reduction of the glycogen stores by a glycogen-depletion protocol the night before the test, fat became an even more important fuel, contributing $70 \%$ to energy expenditure. When these major shifts in substrate utilization are taken into account, exogenous glucose oxidation, expressed as a percentage of total
$\mathrm{CHO}$ oxidation, remained remarkably constant: $42.5 \%$ in the LG trial and $42.6 \%$ in the HG trial.

An explanation for the decreased oral glucose oxidation with low glycogen stores in the muscle may be the elevated plasma FFA concentration in the LG trial. Increased FFA availability is suggested to reduce $\mathrm{CHO}$ oxidation via the glucose-fatty acid cycle, as first described by Randle et al. (27). However, others showed that the classic Randle cycle may not be involved in the regulation of $\mathrm{CHO}$ and fat oxidation during exercise in humans $(4,9)$.

Another explanation for the decreased exogenous glucose oxidation rates observed in the present study may be the lower insulin levels in the LG trial as a result of the glycogen-lowering exercise the night before in combination with the CHO-restricted diet. Insulin concentrations were $30 \%$ lower at the start of exercise and remained lower in the LG trial. Because even small changes in insulin may provoke marked changes in plasma glucose utilization ( $E$. Coyle, personal communication), the lower plasma insulin concentrations after the glycogen-depletion protocol may at

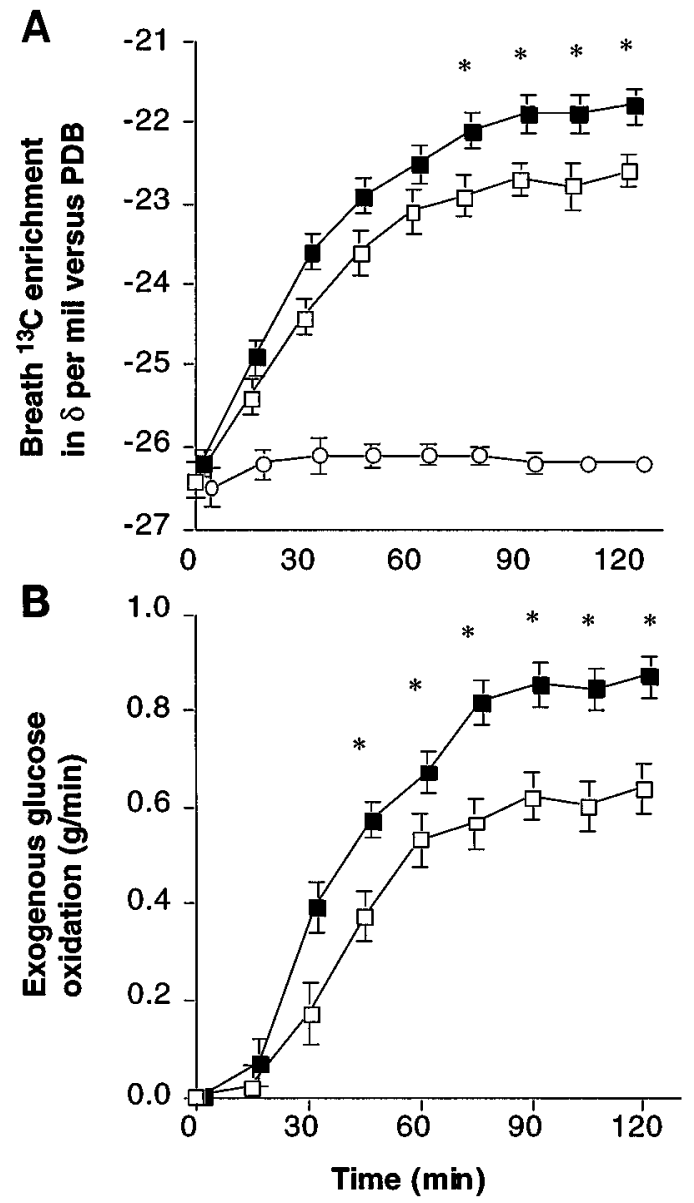

Fig. 3. A: breath ${ }^{13} \mathrm{C}$ enrichment during exercise at $57 \%$ maximal $\mathrm{O}_{2}$ consumption after carbohydrate depletion and carbohydraterestricted diet (LG trial; $\square$ ) and after glycogen loading (HG trial; $\mathbf{0}$ ), both with ingestion of corn-derived glucose, and in a control trial $(O)$ in which potato-derived glucose was ingested. PDB, Pee Dee Bellimnitella. B: exogenous glucose oxidation in HG ( $\square$ ) and LG trials ( $\square$ ). Values are means \pm SE. $*$ Significantly different from $L G$ trial, $P<0.05$. 
least partly explain the decreased exogenous glucose oxidation. Unfortunately, little information is available on the effect of small variations in insulin levels on glucose utilization during exercise.

Ravussin et al. (28) studied oxidation rates of exogenous $\mathrm{CHOs}$ in a group of glycogen-depleted subjects and a control group and found no significant differences. Unfortunately, the study had no crossover design and the glycogen-depletion protocol may have been less exhaustive than the one applied here. Muscle glycogen concentrations were not measured in this study but plasma insulin and FFA concentrations were comparable.

Massicotte et al. (22) studied exogenous $\mathrm{CHO}$ oxidation during $2 \mathrm{~h}$ of exercise in fed and fasted conditions and could not find differences in the exogenous oxidation rates of ingested glucose. This may be due to the fact that $\mathrm{CHO}$ stores may not have been depleted. Fasting will predominantly empty the liver glycogen stores, whereas muscle glycogen stores change little.

Often, increased availability of muscle glycogen is associated with decreased glucose uptake by the muscle $(14,31)$, whereas low muscle glycogen levels are associated with increased muscle glucose uptake (14). Re cently, Hargreaves et al. (13) studied the rate of disappearance of gl ucose in subjects who performed glycogenlowering exercise either 24 or $48 \mathrm{~h}$ before a trial at $65-70 \% \mathrm{Vo}_{2 \max }$ in combination with either a high- or a low-CHO diet. No differences were observed in the $\left({ }^{3} \mathrm{H}\right]$ glucose) tracer-determined rate of disapperance of glucose. Because no plasma glucose oxidation was measured in this study, it cannot be excluded that part of the glucose was used for glycogenesis in the glycogendepleted muscle. However, it is usually assumed that all the glucose taken up by the muscle is also oxidized. If that assumption is true, there were no differences in plasma glucose oxidation between the glycogen-depleted and -loaded trials in the study of Hargreaves et al.

Bosch et al. (1) compared high with normal glycogen stores by investigating $\mathrm{CHO}-$ loaded vs. CHO-nonloaded subjects. They did not observe differences in blood glucose oxidation. In both these studies $(1,13)$, differences between preexercise glycogen concentrations of the high- and normal-to-low-glycogen groups were probably smaller than in the present study. From previous studies we estimate that muscle glycogen concentrations were $\sim 160-190 \mu \mathrm{mol} / \mathrm{g}$ wet wt in the HG trial and below $35 \mu \mathrm{mol} / \mathrm{g}$ wet wt in the LG trial (17). Hargreaves et al. (13) report preexercise values of $96 \mu \mathrm{mol} / \mathrm{g}$ wet wt after exercise and $24 \mathrm{~h}$ on a high-CHO diet and $54 \mu \mathrm{mol} / \mathrm{g}$ wet wt after exercise and $24 \mathrm{~h}$ on a low-CHO diet. Bosch et al. (1) investigated trained cyclists who were either $\mathrm{CHO}$ loaded or nonloaded. Preexercise muscl e glycogen concentrations varied from $194 \mu \mathrm{mol} / \mathrm{g}$ wet wt in loaded to $124 \mu \mathrm{mol} / \mathrm{g}$ wet wt in nonloaded subjects. Although we did not measure muscle glycogen concentrations in the present study, our estimations indicate that differences in muscle glycogen were larger than in other studies.
The different results of the present study compared with other studies are likely attributed to the extent to which muscle glycogen concentrations were reduced and the hormonal disturbances provoked by the exhausting exercise trial the day before. In the present study we used an extremely exhausting exercise protocol that leads to very low muscle glycogen concentrations ( $<35 \mu \mathrm{mol} / \mathrm{g}$ wet wt) (17), high plasma FFA levels, and low plasma insulin levels.

Another possible mechanism could be that ingested glucose is trapped in the liver when it is glycogen depleted. Because the amount of glucose ingested was the same in both the LG and HG trials and exogenous glucose oxidation rates were lower in the LG trial, the question arises as to where the nonoxidized glucose went in the LG trial. It is unlikely that differences in the rate of gastric emptying and/or intestinal absorption in the LG trial compared with the HG trial may explain the differences in oral $\mathrm{CHO}$ oxidation. A more plausible explanation may be storage. Because the size of the plasma glucose pool did not change (similar plasma glucose concentrations), the glucose must have been stored elsewhere, possibly in the liver. It has also been suggested that muscle glycogen synthesis can occur during low-intensity exercise if the muscle is glycogen depleted and if $\mathrm{CHO}$ is ingested $(5,16)$. However, the exercise intensity at which this muscle glycogen synthesis. is observed during exercise is usually lower $\left[<50 \% \mathrm{Vo}_{2 \max }(16,35)\right]$ than the $57 \% \mathrm{Vo}_{2 \max }$ in the present study.

At present, we can only speculate on the fate of this nonoxidized glucose in the LG trial because we did not estimate the rate of appearance of gl ucose from the gut or liver glycogen synthesis.

When the above-mentioned studies are compared, it must not be forgotten, however, that the studies of Hargreaves et al. (13) and Bosch et al. (1) measured blood glucose oxidation, which may be closely correlated to exogenous $\mathrm{CHO}$ oxidation but not necessarily comparable. Exogenous $\mathrm{CHOs}$ have to pass the intestinal wall and enter the liver before appearing in the main circulation from which they can be extracted by the muscle.

The absolute oxidation rates of oral glucose in the present study are somewhat lower than the oxidation rates of maltodextrins in a previous study obtained with the exact same feeding regimen and amount (33). This may be explained by the lower exercise intensity used in the present study. It has been shown that the exogenous substrate utilization is cl osely related to the energy expenditure and thus to the exercise intensity in the range of $45-70 \% \mathrm{Vo}_{2 \max }(20,26)$. In the study of Wagenmakers et al. (33), the exercise intensity was $65 \%$ Wmax (i.e., $70 \% \mathrm{Vo}_{2 \max }$ ), whereas in the present study the exercise intensity was $50 \%$ Wmax $(57 \%$ $\mathrm{V}_{2 \max }$ ). This workload of $50 \% \mathrm{Wmax}$, however, was the highest possible workload to complete a 2-h exercise bout after the glycogen-depletion trial.

In conclusion, the present study shows decreased exogenous glucose oxi dation during prol onged moderateintensity exercise $\left(57 \% \mathrm{VO}_{2 \max }\right)$ after glycogen-lowering 
exercise the evening before the exercise bout and $\mathrm{CHO}$ restriction. It is suggested that incorporation of ingested glucose into liver glycogen, increased plasma FFA levels, and decreased insulin concentrations may be responsible for the observed differences. At present, we can only speculate on the underlying mechanisms.

Address for reprint requests: A. E. J eukendrup, Dept. of Human Biology, Univ. Maastricht, P.O. Box 616, NL-6200 MD Maastricht, The Netherlands (E-mail: A.J eukendrup@HB.RuLimburg.NL).

Received 8 April 1996; accepted in final form 1 J uly 1996.

\section{REFERENCES}

1. Bosch, A. N., S. C. Dennis, and T. D. Noakes. Influence of carbohydrate loading on fuel substrate turnover and oxidation during prolonged exercise. J . Appl. Physiol. 74: 1921-1927, 1993.

2. Bosch, A. N., S. C. Dennis, and T. D. Noakes. Influence of carbohydrate ingestion on fuel substrate turnover and oxidation during prol onged exercise. J . Appl. Physiol . 76: 2364-2372, 1994.

3. Coggan, A. R., and E. F. Coyle. Reversal of fatigue during prolonged exercise by carbohydrate infusion or ingestion. J . Appl. Physiol. 63: 2388-2395, 1987.

4. Coggan, A. R., R. J . Spina, W. M. Kohrt, and J . O. Holloszy. Effect of prolonged exercise on muscle citrate concentration before and after endurance training in men. Am. J . Physiol. 264 (Endocrinol. Metab. 27): E215-E220, 1993.

5. Constable, S. H., R. J . Favier, J . A. McLane, R. D. Fell, M. Chen, and J . O. Holloszy. Energy metabolism in contracting rat skeletal muscle: adaptations to exercise training. Am. J. Physiol. 253 (Cell Physiol. 22): C316-C322, 1987.

6. Costill, D. L., E. Coyle, G. Dalsky, W. Evans, W. Fink, and D. Hoopes. Effects of elevated plasma FFA and insulin on muscle glycogen usage during exercise. J . Appl. Physiol. 43: 695-699, 1977.

7. Coyle, E. F., A. R. Coggan, M. K. Hemmert, and J . L. Ivy. Muscle glycogen utilization during prolonged strenuous exercise when fed carbohydrate. J. Appl. Physiol. 61: 165- 172, 1986.

8. Craig, H. I sotopic standards for carbon and oxygen and correction factors. Cosmochim. Acta 12: 133-149, 1957.

9. Dyck, D. J ., C. T. Putman, G. J . F. Heigenhauser, E. Hultman, and L. L. Spriet. Regulation of fat-carbohydrate interaction in skeletal muscle during intense aerobic cycling. Am. J . Physiol. 265 (Endocrinol. Metab. 28): E 852-E 859, 1993.

10. Gollnick, P. D., B. Pernow, B. Essen, E. J ansson, and B. Saltin. Availability of glycogen and plasma FFA for substrate utilization in leg muscle of man during exercise. Clin. Physiol. Oxf. 1: 27-42, 1981.

11. Gutmann, I., and A. W. Wahlefeld. L-(+)-Lactate, Determination With Lactate Dehydrogenase and NAD (2nd English ed.). New York: Academic, 1974, p. 1464- 1468.

12. Hargreaves, M., B. Kiens, and E. A. Richter. Effect of increased plasma free fatty acid concentrations on muscle metabolism in exercising men. J . Appl. Physiol. 70: 194-201, 1991.

13. Hargreaves, M., G. McConell, and J . Proietto. Influence of muscle glycogen on glycogenolysis and glucose uptake during exercise in humans. J . Appl. Physiol. 78: 288-292, 1995.

14. Hespel, P., and E. A. Richter. Glucose uptake and transport in contracting, perfused rat muscle with different pre-contraction glycogen concentrations. J . Physiol. Lond. 427: 347-359, 1990.

15. J eukendrup, A. E., W. H. M. Saris, R. Van Diesen, F. Brouns, and A. J . M. Wagenmakers. Effect of endogenous carbohydrate availability on oral medium-chain triglyceride oxidation during prolonged exercise. J . Appl. Physiol. 80: 949-954, 1996.

16. Kuipers, H., H. A. Keizer, F. Brouns, and W. H. M. Saris. Carbohydrate feeding and glycogen synthesis during exercise in man. Pfluegers Arch. 410: 652-656, 1987.

17. Kuipers, H., W. H. M. Saris, F. Brouns, H. A. Keizer, and C. ten Bosch. Glycogen synthesis during exercise and rest with carbohydrate feeding in males and females. Int. J . Sports Med. 10, Suppl. 1: S63-S67, 1989.

18. Kuipers, H., F. T. J . Verstappen, H. A. Keizer, P. Geurten, and G. van Kranenburg. Variability of aerobic performance in the laboratory and its physiologic correlates. Int. J . Sports Med. 6: 197-201, 1985.

19. Maehlum, S., P. Felig, and J . Wahren. Splanchnic glucose uptake and muscle glycogen metabolism after feeding during postexercise recovery. Am. J . Physiol 241 (Endocrinol . Metab. 4): E255-E260, 1978.

20. Massicotte, D., F. Péronnet, E. Adopo, G. R. Brisson, and C. Hillaire-Marcel. Effect of metabolic rate on the oxidation of ingested glucose and fructose during exercise. Int. J . Sports M ed. 15: 177-180, 1994

21. Massicotte, D., F. Péronnet, G. Brisson, K. Bakkouch, and C. Hillaire-Marcel. Oxidation of a glucose polymer during exercise: comparison with glucose and fructose. J . Appl. Physiol. 66: 179-183, 1989

22. Massicotte, D., F. Péronnet, G. Brisson, L. Boivin, and C. Hillaire-Marcel. Oxidation of exogenous carbohydrate during prolonged exercise in fed and fasted conditions. Int. J. Sports Med. 11: 253-258, 1990.

23. McConell, G., S. Fabris, J . Proietto, and M. Hargreaves. Effect of carbohydrate ingestion on glucose kinetics during exercise. J . Appl. Physiol. 77: 1537-1541, 1994.

24. Péronnet, F., and D. Massicotte. Table of nonprotein respiratory quotient: an update. Can. J . Sport Sci. 16: 23-29, 1991.

25. Pirnay, F., M. Lacroix, F. Mosora, A. Luyckx, and P. Lefèbvre. Glucose oxidation during prol onged exercise evaluated with naturally labeled $\left.{ }^{13} \mathrm{C}\right]$ glucose. J . Appl. Physiol. 43: 258-261, 1977.

26. Pirnay, F., A. J . Scheen, J . F. Gautier, M. Lacroix, and P. J . Lefèbvre. Exogenous glucose oxidation during exercise in relation to the power output. Int. J . Sports Med. 16: 456-460, 1995.

27. Randle, P. J ., C. N. Hales, P. B. Garland, and E. A. Newsholme. The glucose-fatty acid cycle: its role in insulin sensitivity and the metabolic disturbances if diabetes mellitus. Lancet 1 : 785-789, 1963.

28. Ravussin, E., P. Pahud, A. Dorner, M. J . Arnaud, and E. J equier. Substrate utilization during prolonged exercise pre ceded by ingestion of ${ }^{13} \mathrm{C}$-glucose in glycogen depleted and control subjects. Pfluegers Arch. 382: 197-202, 1979.

29. Rehrer, N. J ., A. J . M. Wagenmakers, E. J . Beckers, D. Halliday, J . B. Leiper, F. Brouns, R. J. Maugham, K. Westerterp, and W. H. M. Saris. Gastric emptying, absorption, and carbohydrate oxidation during prolonged exercise. J . Appl. Physiol. 72: 468-475, 1992.

30. Rennie, M. J ., and W. W. Winder. A sparing effect of increased plasma fatty acids on muscle and liver glycogen content in the exercising rat. Biochem. J . 156: 647-655, 1976.

31. Richter, E. A., and H. Galbo. High glycogen levels enhance glycogen breakdown in isolated contracting skeletal muscle. J. Appl. Physiol. 61: 827-831, 1986.

32. Vukovich, M. D., D. L. Costill, M. S. Hickey, S. W. Trappe, K. J . Cole, and W. J . Fink. Effect of fat emulsion infusion and fat feeding on muscle glycogen utilization during cycle exercise. J . Appl. Physiol. 75: 1513-1518, 1993.

33. Wagenmakers, A. J . M., F. Brouns, W. H. M. Saris, and D. Halliday. Oxidation rates of orally ingested carbohydrates during prolonged exercise in man. J. Appl. Physiol. 75: 2774-2780, 1993.

34. Wagenmakers, A. J . M., N. J . Rehrer, F. Brouns, W. H. M. Saris, and D. Halliday. Breath ${ }^{13} \mathrm{CO}_{2}$ background enrichment at rest and during exercise: diet-related differences between Europe and America. J . Appl. Physiol. 74: 2353-2357, 1993.

35. Yaspelkis, B. B., III, J . G. Patterson, P. A. Anderla, Z. Ding, and J . L. Ivy. Carbohydrate supplementation spares muscle glycogen during variable-intensity exercise. J . Appl. Physiol. 75: 1477-1485, 1993. 